\title{
EHMTI-0110. Epidemiology of primary headaches in the population of Baku
}

\author{
R Aliyev ${ }^{1 *}$, R Shiraliyeva ${ }^{1}$, R Hasanov $^{1}$, A Mammadbayli ${ }^{2}$ \\ From 4th European Headache and Migraine Trust International Congress: EHMTIC 2014 \\ Copenhagen, Denmark. 18-21 September 2014
}

\section{Introduction}

Headache is one of the most common reasons people see physicians. It has been estimated that $47 \%$ of the adult population have headache at least once within last year in general.

That is why the aim of the study was to investigate the prevalence of primary headaches in the population of Baku the capital of Azerbaijan.

\section{Methods}

Baku consists of eleven districts. During 2010-2012 years every 30th of 45,000 Nasimi district habitants were invited to the clinic for an interview and screening of headaches. Only one district habitants were involved to the study. Currently, the total population of district is 202,073 people. The study included 1,300 people. With the help of a standardized questionnaire, have studied the presence of headache, their specificity, the type, risk factors, neurologi$\mathrm{cal}$ and somatic status of the respondents, their social and economic status. Diagnosis of headache conducted according to the criteria of the International Classification of Headache (second edition).

\section{Results}

In $40.5 \%$ of the respondents in the last 6 months there has been a headache. $13.7 \%$ of them were men, $26,3 \%$ were women. At $18.2 \%$ had migraine, $42.2 \%$ have tension type headaches. Distribution headaches by sex showed predominance of primary headaches among women $(2: 1)$. Primary headaches are other character (cluster, paroxysmal hemicrania, etc.) revealed only a few people that had no practical meaning. The remaining 183 people (34.7\%) were diagnosed secondary headaches.

${ }^{1}$ Neurology Department, Azerbaijan State Advanced Training Institute for Doctors named after A.Aliyev, Baku, Azerbaijan

Full list of author information is available at the end of the article
In conclusion our findings may be helpful in organizing the treatment and prevention measures of headaches in Baku.

No conflict of interest.

\section{Authors' details}

${ }^{1}$ Neurology Department, Azerbaijan State Advanced Training Institute for Doctors named after A.Aliyev, Baku, Azerbaijan. ${ }^{2}$ Department of Neurology and Medical Genetics, Azerbaijan Medical University, Baku, Azerbaijan.

Published: 18 September 2014

doi:10.1186/1129-2377-15-S1-B14

Cite this article as: Aliyev et al:: EHMTI-0110. Epidemiology of primary headaches in the population of Baku. The Journal of Headache and Pain 2014 15(Suppl 1):B14.

\section{SpringerOpen ${ }^{\circ}$}

C 2014 Aliyev et al; licensee Springer. This is an Open Access article distributed under the terms of the Creative Commons Attribution License (http://creativecommons.org/licenses/by/2.0), which permits unrestricted use, distribution, and reproduction in any medium, provided the original work is properly cited.
Submit your manuscript to a SpringerOpen ${ }^{\circ}$ journal and benefit from:

- Convenient online submission

- Rigorous peer review

- Immediate publication on acceptance

- Open access: articles freely available online

- High visibility within the field

- Retaining the copyright to your article

Submit your next manuscript at $>$ springeropen.com 
